\title{
Una tradición perdida de don Ricardo Palma
}

\author{
César Coloma Porcari \\ Instituto Latinoamericano de Cultura y Desarrollo \\ sillardearequipa@gmail.com \\ Lima-Perú
}

\section{Resumen}

Trabajo de investigación referente a una olvidada tradición de don Ricardo Palma narrada personalmente por él a don José Carrasco Torrico, político, escritor y periodista boliviano, en Lima, el año 1907. Publicada por el Dr. Carrasco Torrico ese año, ha permanecido en el más completo olvido durante ciento doce años. Esta tradición fue redescubierta por el autor de este texto el año 2019 y se reproduce al final del mismo.

Palabras clave: Ricardo Palma, tradiciones, folclore, relaciones entre el Perú y Bolivia.

\begin{abstract}
This is research work concerning a forgotten Tradition of Ricardo Palma, personally narrated by him to don José Carrasco Torrico, a Bolivian politician, writer and journalist, in Lima in 1907. Published by Dr. Carrasco Torrico that year, it has remained in the most complete oblivion for a hundred and twelve years. This Tradition was rediscovered by don César Coloma Porcari in 2019 and it is reproduced in this essay.
\end{abstract}

Keywords: Ricardo Palma, traditions, folklore, relations between Peru and Bolivia. 
César Coloma Porcari (Perú): Presidente del Instituto Latinoamericano de Cultura y Desarrollo, Miembro de Número del Instituto Ricardo Palma, Miembro del Centro de Estudios Históricos Militares del Perú. 
En el Centenario del fallecimiento del gran maestro don Ricardo Palma sacamos a la luz una pequeña tradición que encontramos recogida por un destacado hombre público boliviano. Esta tradición breve, aunque de gran calidad, ha permanecido en el olvido más absoluto durante ciento doce años. Fue publicada en una de las decenas de miles de páginas impresas de la prensa arequipeña. Afortunadamente nosotros encontramos este texto desconocido y olvidado.

Nos referimos a la tradición "Cómo contraje matrimonio", que el año 1907, el célebre tradicionista se la relatara personalmente al Dr. José Carrasco Torrico, ilustre político, periodista y escritor cochabambino, en una visita que este le hiciera en la Biblioteca Nacional de Lima

Cabe destacar el gran interés del notable altoperuano de redactar la tradición que escuchó de la boca del mismo Palma. Como eximio periodista que era, pudo registrarla al pie de la letra, rescatando para la posteridad esta pequeña aunque valiosa obra palmista, en una carta suya publicada en la prensa peruana. El Dr. Carrasco afirmaba en su escrito que "He aquí una tradición contada por el mismo Palma y que es digna de ser conocida", tal como lo veremos más adelante.

En la página 1 del diario arequipeño El Deber $\mathrm{N}^{\circ} 4847$, del jueves 2 de mayo de 1907, fue publicada aquella bajo el titular de "Don Ricardo Palma/Como contrajo matrimonio/Relación desconocida".

Se debe tener presente que el diario El Deber era un periódico perteneciente a la iglesia católica arequipeña. Su primer número apareció el viernes 31 de octubre de 1890, y se publicó durante setenta y dos años, ininterrumpidamente. Lamentablemente dejó de aparecer el 30 de septiembre de 1962, indicándose, en un aviso publicado en la primera página, que el diario ya no se publicaría más "por razones económicas insuperables". 
En el mencionado diario de Arequipa, en su edición del jueves 2 de mayo de 1907, como ya lo mencionamos, se informaba que

El distinguido hombre público boliviano don José Carrasco -que acaba de estar en Lima- ha escrito en una carta la siguiente relación, que seguramente será leída con interés en todas partes: "En compañía de Ricardo Mujía, Encargado de Negocios de Bolivia en Lima, nos encaminamos ayer a la Biblioteca Nacional. Allí encontramos al ilustre y simpático viejo don Ricardo Palma, que nos recibió con finísima galantería. Conoce a Bolivia bastante; ha tratado con muchos de sus hombres públicos; sostiene que el Perú y Bolivia tienen vínculos e intereses indestructibles, y sabe que progresamos con un plan ferroviario que hará prodigios, dadas las inmensas riquezas del país".

Agrega el Dr. Carrasco que "La conversación rodó sobre diversos temas y la visita se prolongó. Entre otras cosas, no resistió a la tentación de contar el incidente más trascendental de la vida de este insigne literato". Señala además que "Recordamos que en Bolivia las familias eran muy largas; que se casaban muy jóvenes, y a ese propósito nos refirió el incidente de su matrimonio".

El Dr. Carrasco recuerda también que "El señor Palma cumplió el 7 del mes que rige, 74 años, y está lozano y fresco; promete vivir todavía para bien no solo de su patria sino de la humanidad". Y afirma, finalmente, que "He aquí una tradición contada por el mismo Palma y que es digna de ser conocida, por referirse a uno de los más ilustres escritores de la América del Sur".

Cabe señalar que don Ricardo Palma, el año 1876, contrajo matrimonio con doña Cristina Román. Cuatro años antes de esa boda (en 1872), había nacido su hijo don Clemente Palma, otro destacado escritor peruano, fallecido en 1946. Por ello le pregunta a su posible novia si " ¿Quiere usted ser madrastra?". Y 
agrega el tradicionista que "He decidido casarme y la he elegido para mi esposa", como puede leerse en la transcripción de la tradición palmista que rescatamos.

El tradicionista -suponemos- antes de contraer matrimonio fue muy crítico de este sacramento y lo llegó a comparar, sarcásticamente -como lo veremos más adelante- con el mismo "infierno", y a la madre política la calificaba como "boa constrictor", añadiendo él que esta era un ser "más feroz que tigre cebado", y similar a las "serpientes de cascabel".

\section{El redactor}

Don José Carrasco Torrico (Totora, Cochabamba, 1863-La Paz, 1921) fue un notable político, escritor y periodista, y fundó el periódico El Diario de La Paz. Este periódico es "el más antiguo que aún se publica” en Bolivia (Canelas, 1999, p. 17). Fue autor de Estudios Constitucionales (La Paz, González y Medina, 1920, 4 vols.) y de Bolivia ante la Liga de las Naciones (Lima, Librería e Imprenta Gil, 1920), entre otras obras no menos importantes.

Este destacado estadista boliviano estudió Derecho en la Universidad de San Simón, en Cochabamba, se recibió de abogado en 1885 y se dedicó a la agricultura en sus propiedades en Totora. Desde 1893 dirigió El Comercio de Cochabamba. En 1900 fue nombrado gobernador de Oruro, luego sería designado ministro de Guerra y más tarde, ministro de Justicia y del Interior. En 1908 fue nuevamente nombrado ministro del Interior, y en 1910, siendo congresista, fue elegido presidente de la Cámara de Diputados, y reelegido en cuatro periodos, sucesivamente. El 4 de mayo de 1913 fue elegido vicepresidente de la República de Bolivia (Unión Panamericana, 1921, p. 309). 
El Dr. Carrasco utilizó el pseudónimo de "Brissot" (Botelho, 1980, p. 168); y en publicaciones especializadas bolivianas se registra que fue "periodista, escritor, internacionalista, tratadista de Derecho Constitucional" (Guzmán, 1983, p. 41), y "Gran parte de su vida la consagró a la actividad periodística como director-fundador de El Comercio de Cochabamba (1893) y El Diario de la Paz (1904-1921)" (Arze, 1984, p. 58). Señalan asimismo que fue "Periodista, político, parlamentario y diplomático de vasta trayectoria en cada uno de los predios mencionados" (Quintana, 1992, p. 161).

Otros autores afirman que el Dr. Carrasco "pertenece, en efecto, al grupo de los hombres calificados como eminentes, por descollar en forma extraordinaria" (Escalante, 1914, p. 230), y que "El patriotismo verdadero del Dr. José Carrasco le hizo desear para su patria una mejor situación que le permitiera desarrollar su comercio y todas las fuerzas de actividad con que cuenta su país" (Federación de Estudiantes del Perú, 1920, p. 82). Por último, fue un "defensor de los derechos mancomunados del Perú y Bolivia ante los desplantes de la fuerza" (Federación de Estudiantes del Perú, 1920, p. 106).

\section{El representante diplomático}

Don Ricardo Mujía Linares (Chuquisaca, 1861-1934) acompañó al Dr. José Carrasco Torrico en la visita que este último le hizo a don Ricardo Palma, como ya lo indicamos. El Dr. Mujía fue Encargado de Negocios de Bolivia en el Perú. Fue

Poeta, dramaturgo e historiador. Abogado (1886), se desempeñó como maestro de colegio y docente universitario. Tuvo intensa actividad política y diplomática. Por cortos periodos, Ministro de Gobierno y Fomento (1917) y de Relaciones y Culto (1917). Actuó en misiones en Brasil, el Perú, Paraguay, Uruguay y Argentina (Blanco, 2005, p. 125). 
Entre sus obras publicadas se encuentran la monumental BoliviaParaguay (8 vols., La Paz, Empresa Editora El Tiempo, 1914); así como su libro de poesía Penumbras (Barcelona, Tipografía de Dionisio Brull, 1898).

\section{El Perú y Bolivia}

Las relaciones comerciales entre el Bajo y el Alto Perú fueron siempre muy intensas. Por medio del arrieraje se trasladaban los bienes de un lugar a otro, a través de conocidas rutas por donde circulaban los mercaderes con sus recuas de llamas, mulas y caballos.

Las ciudades altoperuanas (La Paz, Chuquisaca, Potosí, Oruro y Tarija) estaban unidas de esta manera con Puno y el Cuzco, así como con Arequipa y Moquegua, Huamanga y Huancavelica, e inclusive con la Ciudad de los Reyes, la capital del Virreinato.

La llegada del ferrocarril facilitó ese comercio, enlazándose el puerto de Mollendo con Arequipa y el puerto de Puno, en el lago Titicaca. Desde allí se continuaba viaje en un navío hasta llegar al puerto de Guaqui, en la orilla boliviana del lago, reembarcándose por tierra hasta La Paz.

Esta gran relación comercial permitió también que se acrecentara la amistad y relaciones entre las familias de la clase señorial del sur del Perú y de Bolivia. Los políticos altoperuanos, por medio del ferrocarril, llegaban a la ciudad de Arequipa, en donde eran muy apreciados, y se embarcaban en el puerto de Mollendo, aprovechando las ventajas que este ofrecía, al estar conectado por la vía marítima con los principales puertos del mundo, gracias a los eficientes servicios de las más importantes empresas navieras que tenían como escala a Mollendo. 
Las relaciones comerciales entre el Perú y Bolivia alcanzaron su mayor esplendor al establecerse el servicio ferroviario internacional, de Mollendo a Buenos Aires, el año 1925, "Ese año, con motivo del Centenario de la República de Bolivia (6 de agosto de 1925), se inauguró el tramo de línea férrea que faltaba para unir el ferrocarril argentino con el boliviano y peruano" (Coloma Porcari, 2018, El Pueblo, p. 8).

Además, "Este tramo, de 203 kilómetros de largo, unía el pueblo de Atocha, ubicado en la provincia de Sud Chichas, departamento de Potosí, con la ciudad de Villazón, situada en la provincia Modesto Omiste del mismo departamento"; fue construido siendo Presidente de Bolivia el Dr. Juan-Bautista Saavedra y Mallea (La Paz, 1870-Santiago de Chile, 1939). El Presidente Saavedra fue el gran promotor de la construcción de esa importantísima línea férrea (Coloma Porcari, 2018, El Pueblo, p. 8).

Asimismo,

Montevideo y los ferrocarriles uruguayos también estaban conectados con Mollendo, por la vía de Buenos Aires. Las empresas propietarias de los ferrocarriles en el Perú, Bolivia y la Argentina, gracias a una hábil coordinación, pudieron ofrecer al público boletos de viaje entre los dos puntos extremos: Buenos Aires y Mollendo (Coloma Elías, 2008: 10).

Es importante señalar que

Muchos viajeros utilizaron ese Ferrocarril trans-Continental, inclusive altas autoridades, políticos y diplomáticos, habiéndose mantenido el servicio hasta mediados del siglo XX. Fue un medio de unión entre el Perú, la Argentina y Bolivia, que sirvió para el comercio en gran escala y el intercambio cultural. Es necesario que se rehabilite el 
servicio, como una manera de fomentar la integración entre esos países hermanos (ibíd.).

El viaje de Mollendo a Buenos Aires y viceversa tenía una duración de siete días y medio, y

Cabe recordar que para atravesar el lago Titicaca se había establecido un servicio de vapores que transportaban a los pasajeros y carga entre los terminales de Puno, en el Perú, y Guaqui, en Bolivia. Del ferrocarril se pasaba al vapor y viceversa, de una manera completamente sincronizada. Y el Uruguay también estaba conectado con Mollendo, debido a que Montevideo, su capital, al encontrarse en la orilla opuesta del río de la Plata, estaba enlazado con Buenos Aires por la vía fluvial.

$[\ldots]$

Es admirable la manera cómo todas las empresas británicas propietarias de los ferrocarriles del Perú, Bolivia y la Argentina, debido a una eficiente coordinación, lograron ofrecer al público los boletos para el viaje entre Mollendo y Buenos Aires. Así se anunciaba en la prensa de la época (Coloma Porcari, 2018, El Pueblo, p. 8).

La unión de los servicios ferroviarios del Perú, Bolivia y la Argentina, beneficiaron de una manera notable a Bolivia, debido a que la pusieron en contacto directo con un importante puerto del Pacífico (Mollendo) y con otro del Atlántico (Buenos Aires), con un servicio de gran calidad y perfectamente organizado y eficiente.

Lamentablemente ese servicio integral no existe más debido a que fue suprimido en la década de 1970. Las líneas férreas se conservan en su totalidad, pero están dedicadas al servicio interno de cada país. Creemos que es una necesidad apremiante el que se reinicie el tráfico sincronizado de personas y 
mercaderías, en las líneas férreas de los tres países, tal como ocurrió, con tan beneficiosos resultados, desde el año 1925.

\title{
El matrimonio en las tradiciones de Palma
}

En "Los amantes de Real Orden" (Palma, 1968, p. 130-134), cuenta el tradicionista que en el siglo XVI, durante el reinado de don Felipe II, se dispuso que "todos los estantes y habitantes de la muy noble ciudad de los Reyes" contrajesen matrimonio en un término de treinta días. Y que "los que no tuviesen un arreglillo o aparejada novia, recibiesen costilla de Real Orden, y fuese ésta la chica que la Audiencia escogiese entre las indias nobles del país".

La razón de esta medida tomada por el monarca para casar forzadamente a los conquistadores y primeros vecinos solteros era que con ella pensaban que "desaparecerá todo olor a barraganía, habrá la moral ganancia y se amansarán los genios turbulentos; que con viento se limpia el trigo y los vicios con castigo". Palma termina esta tradición "diciendo a guisa de oración jaculatoria: -Bendito y alabado sea el Señor, que nos hizo nacer en tiempos en que ningún hijo de vecino corre el riesgo de que lo casen por Real Orden".

\section{Matrimonio e infierno}

Debemos recordar que en la tradición "Creo que hay infierno" (1968, pp. 736-738), compara al matrimonio, sarcásticamente, con el mismo infierno. En ella se refiere a un personaje jaranista e irreverente, y que "rasgueaba lindamente la guitarra y cantaba:

\author{
La prima del cura \\ de Chuchurumbel \\ por no hacer dos camas \\ se acuesta con él".
}


Asimismo, este personaje, llamado Pepete, decía en público, en un país en donde no existía la libertad religiosa, que él no creía en la existencia del infierno. Y un día, discutiendo con un sacerdote, le dijo a este que "eso del infierno es cuento de frailes borrachos para embaucar beatas".

El tradicionista cuenta que "El cura se empeñó por probar por $a+b$ que hay infierno, purgatorio y limbo, esto es, tres cárceles penitenciarias", pero no logró su cometido ya que el hereje no cambiaba de parecer. Por ello el fraile tomó la decisión de excomulgarlo.

El infeliz Pepete se vio entonces en peligro de ser quemado vivo por la turba, y decidió ir a Lima para hablar con el arzobispo, quien lo escuchó y para salvarlo le aplicó una penitencia que le iba a resultar casi apocalíptica.

Regresó a su pueblo y el párroco levantó la excomunión, y “para que viviese en gracia de Dios, se le forzó a contraer matrimonio con una hembra de peor carácter que un tabardillo entripado, con la cual hacía meses mantenía no sé qué brujuleos pecaminosos". Y Palma agrega que "Ítem (y el ítem es cola de pavo real), la novia le traía una suegra más feroz que tigre cebado".

Por último, el tradicionista cuenta que

Desde entonces, Pepete se dio un par de puntadas en la boca y no volvió a meterse en filosofías. A lo sumo, cuando su mujer le armaba un tiberio y la suegra lo arañaba, se conformaba con murmurar:

-iVaya si tuvo razón el padre cura! Ahora sí creo en el infierno, porque con suegra y mujer, lo tengo metido en casa. 


\title{
Las madres políticas
}

El tradicionista la emprende contra las madres políticas en "Los amantes de Real Orden" (1968, pp. 131-134). Allí cuenta que en el siglo XVI "a la moda estuvo entonces el cantarcillo:

\author{
Si nadie quiere suegra \\ yo si la quiero \\ para a falta de leña \\ tirarla al fuego".
}

Y agrega don Ricardo que "tiene razón que le sobra el cantarcillo. El padre Noé embarcó en el arca todo linaje de alimañas y sabandijas ponzoñosas; pero se cuidó mucho de no embarcar suegra".

En esta tradición se refiere asimismo a un personaje que huyó de matrimonio diciendo "-iA cabalgar caballeros!... iQue nos casan, que nos casan! ¿Suegra conmigo? iNones! De azúcar hubo una, y hasta esa amargó". Manifiesta además, "Que quiero estar tan lejos yo de una suegra como las golondrinas de las estrellas". Y termina haciéndose la pregunta siguiente: "iTienen ustedes la bondad de decirme de donde diablos han salido después las suegras?”.

En otra tradición, titulada "Glorias del cigarro" (1968, p. 1444) reproduce una conversación con el propietario de una cigarrería limeña. En esta le pregunta "¿Y qué dice usted sobre la influencia del cigarro en la paz doméstica? ¿Tiene un marido alguna desazón con el boa constrictor llamado suegra?". Y el tradicionista agrega allí que

"La suegra es el eximio divisor,
y la pobreza el aislador mejor". 
Afirma además que el cigarrero,

Pues en vez de coger una estaca y derrengar a la vieja, y que se arme una sarracina y acuda la guardia urbana y la policía preventiva y las demás instituciones de moda, coge un Flor de Lima [cigarro] o un Chalaco [cigarro], restrega un fósforo y se echa a contemplar las espirales del humo. Desengáñese usted. Nada hay como el tabaco para volver bobas hasta a las culebras de cascabel.

Asimismo, en la tradición "Dónde y cómo el diablo perdió el poncho" (1968, pp. 912-913) cuenta que una vez se apareció en Ica el Señor Jesucristo con San Pedro, y que en esos días fue esa ciudad "un remedo de la gloria". Además, en ese tiempo "No ocurrió la menor pelotera en los matrimonios y, lo que es verdaderamente milagroso, se les endulzó la ponzoña a las serpientes de cascabel que un naturalista llama suegras y cuñadas". Pero una vez que el Señor y su comitiva se retiraron de Ica, "las suegras se propusieron sacarles los ojos a los yernos, las mujeres se tornaron pedigüeñas y antojadizas de joyas y trajes de terciopelo $[\ldots] "$.

\section{Conclusiones}

La breve tradición "Cómo contraje matrimonio", de don Ricardo Palma, recogida y publicada el año 1907 por el destacado hombre público boliviano Dr. José Carrasco Torrico, y rescatada del olvido por nosotros, es importante debido a que acrecienta la gran obra del tradicionista.

Se le debe reconocer al Dr. Carrasco el mérito de haber recogido y publicado, el año mencionado, esta breve tradición que se la narró verbalmente don Ricardo Palma en una visita que le hizo a él. 
Esta tradición, por su estilo, tiene las características propias de la obra de Palma, mostrando una fina ironía sobre lo que representa el matrimonio. Nos brinda, además, pormenores sobre su noviazgo con doña Cristina Román, quien sería su amada y fiel esposa hasta el fallecimiento de ella, hecho ocurrido el 28 de enero de 1911, "en los altos de la Biblioteca Nacional", en donde residía con su esposo, Director de la misma, y sus hijos.

A continuación ofrecemos la transcripción de esta tradición.

\section{Cómo contraje matrimonio}

Tradición de don Ricardo Palma recogida por don José Carrasco Torrico (1907)

Recuperada por don César Coloma Porcari (2019)

“Tenía 43 años y entonces creí que debía casarme. Hice una lista de todas las muchachas que me parecían casaderas y comencé una prolija selección. La primera vi que no me convenía. A la segunda no le convenía yo; y así, fui borrando de la lista la mayor parte, hasta dejar solo tres que me parecían las mejores. Escribí sus nombres en tres papeles, me saqué la gorra y después de confundir los tres nombres, me decidí a sacar por suerte a mi novia. Si saldrá anguila o culebra, decía, y saqué la papeleta. Salió Cristina. Perfectamente.

"Me encaminé a la casa de la novia. Allí me recibieron con algazara, haciéndome cargos de mis frecuentes ausencias. Mi salutación fue ésta:

“- Vengo a visitarlas largo, voy a quedarme a comer con ustedes.

"Celebraron mi resolución. En la comida me senté al lado de Cristina y la dije:

“- ¿Quiere usted ser madrastra? He decidido casarme y la he elegido para mi esposa.

“- Puñalada de pícaro -me replicó.

"Yo le afirmé mi resolución y le di término para que piense y resuelva. Cumplido él, recibí respuesta favorable. 
"En ese momento jugaba el padre de Cristina rocambor con sus amigos, pedí perdón de éstos, llamé a un lado al caballero y le pedí la mano de su hija.

"Me repuso que era asunto de ella y la llamó para consultarla. Dada la respuesta, todo estaba hecho. De esta manera hice la felicidad de mi hogar".

\section{Bibliografía}

Arze, J. R. (1984). Diccionario biográfico boliviano: Figuras bolivianas en las ciencias sociales. Cochabamba: Editorial Los amigos del Libro.

Blanco, E. (2005). Enciclopedia Gesta de autores de la literatura boliviana. La Paz: Plural Editores.

Botelho, R. (1980). El litoral boliviano: perspectiva histórica y geopolítica. La Paz: El Cid, Editor.

Canelas, F. (1999). Bolivia, el milenio: el siglo XX en Sucre, La Paz, Cochabamba y el mundo. La Paz: Editorial Canelas.

Coloma Elías, G. W. (2008). El castillo Forga y el Ferrocarril TransContinental de Mollendo a Buenos Aires. Lima: Instituto Latinoamericano de Cultura y Desarrollo.

Coloma Porcari, C. (2018). El Ferrocarril Trans-Continental de Mollendo a Buenos Aires; en: El Pueblo, Arequipa, sábado 6 de enero de 2018, p. 8.

Escalante Gómez, M. (1914). Mundo Hispano Americano: bosquejos crítico-biográficos. París: $s$. p. $i$.

Federación de Estudiantes del Perú (1920): Studium, vol. II, № 4, Lima.

Guzmán, A. (1983). El Ensayo en Bolivia, Cochabamba: Editorial Los Amigos del Libro.

Palma, R. (1968): Tradiciones Peruanas Completas. Madrid: Aguilar S. A. de Ediciones, Selecciones Gráficas. 
Quintana Condarco, R. (1992). Pasión por la palabra: El periodismo boliviano a través de sus protagonistas. La Paz: Producciones Cima.

Unión Panamericana (1921): Bulletin of the Pan American Union, vol. LIII, Washington, D. C., julio-diciembre.

Recibido el 18 de octubre de 2019 Aceptado el 2 de noviembre de 2019. 